Research Article

\title{
Drug prescribing pattern in ulcerative colitis in a tertiary care hospital: an observational study
}

\author{
Mukunda Narayanareddy ${ }^{1 *}$, Eesha B. R. ${ }^{2}$, Tara V. Shanbhag ${ }^{3}$, Smita Shenoy $^{4}$
}

\author{
${ }^{1}$ Assistant Professor, \\ Department of Pharmacology, \\ M.S. Ramaiah Medical College, \\ Bangalore, India \\ ${ }^{2}$ Associate Professor, \\ Department of Pharmacology, \\ Kodagu Institute of Medical \\ Sciences, Kodagu, India, \\ ${ }^{3}$ Professor and Head, \\ Department of Pharmacology, \\ Srinivasa Medical College, \\ Suratkal, India, \\ ${ }^{4}$ Additional Professor, \\ Department of Pharmacology, \\ Kasturba Medical College, \\ Manipal University, Manipal, \\ India
}

Received: 01 August 2016

Accepted: 06 August 2016

*Correspondence to:

Dr. Mukunda Narayanareddy,

Email: drmukundagm@

gmail.com

Copyright: (C) the author(s), publisher and licensee Medip Academy. This is an openaccess article distributed under the terms of the Creative Commons Attribution NonCommercial License, which permits unrestricted noncommercial use, distribution, and reproduction in any medium, provided the original work is properly cited.

\begin{abstract}
Background: Ulcerative colitis (UC) is an inflammatory disease of colon and rectum of uncertain etiology. The clinical course of UC is marked by exacerbations and remissions. Furthermore there is limited data available on the management of ulcerative colitis from India. Hence, the present study was undertaken to study the drug prescribing pattern in ulcerative colitis.

Methods: A retrospective case record based observational study was done at Kasturba Hospital, Manipal, India from $1^{\text {st }}$ January 2009 to $31^{\text {st }}$ December 2010. Patients diagnosed to have UC during our study period based on clinical, endoscopic and histopathological evidence were included in the study. SPSS 17 software package was used for statistical calculations. Descriptive statistics was used to analyze the data.

Results: The total number of patients diagnosed to have UC during our study period was 83.The peak incidence of disease was in the age group of 30-39 years and it was more common in males. The prescription rate of aminosalicylates, glucocorticoids and immunosuppressants were 96.3, 54.3, and $18.5 \%$ respectively. Mesalamine, prednisolone, and azathioprine were the commonly prescribed drugs in each class. The commonly prescribed treatment regimen was combination of aminosalicylates with glucocorticoids (43.2\%).

Conclusions: Ulcerative colitis was more common in males. Aminosalicylates were the commonly prescribed drugs and a combination of aminosalicylate and steroid was frequently used regimen in our study.
\end{abstract}

Keywords: Ulcerative colitis, Drug prescribing pattern, Aminosalicylates, Immunosuppressants, Glucocorticoids

\section{INTRODUCTION}

Ulcerative colitis (UC) is the inflammatory disease of colon and rectum of uncertain etiology first described in 1875. ${ }^{1}$ The most characteristic clinical symptom is bloody diarrhea often with prominent symptoms of rectal urgency and tenesmus. The clinical course of UC is marked by exacerbations and remissions, which may occur spontaneously or in response to treatment changes or intercurrent illnesses. The peak age of onset for UC is between 15 and 25 years. A second, lesser peak of incidence has also been noted in some series, between 55 and 65 years. There is an approximately equal incidence in both males and females. ${ }^{2}$ Ulcerative colitis is considered to be uncommon in India; however several recent reports have shown that there is a trend towards an 
increased incidence of ulcerative colitis here as well. The prevalence and incidence of UC in India are 42.844.3/lakh and 6.02/lakh respectively. ${ }^{3-5}$ Furthermore, there is limited data available on the management of ulcerative colitis from India. Hence, the present study was undertaken to analyze the different treatment strategies being employed for UC in a tertiary care hospital.

\section{METHODS}

A retrospective case record based study was carried out (from $1^{\text {st }}$ January 2009 to $31^{\text {st }}$ December 2010) after obtaining approval from the University Ethics Committee. Patients diagnosed to have UC during our study period based on clinical, endoscopic and histopathological evidence were included in the study. The case records were collected from medical records section. We designed a proforma to study the drug prescribing pattern which contained relevant information such as patient demographics (age, gender), clinical data (symptoms, laboratory findings), treatment data (drugs prescribed - generic/brand name, dosage, route, and frequency of administration). SPSS 17 software package was used for all statistical calculations. Descriptive statistics was used to analyze the data. The graphs were prepared using Microsoft Excel package. ${ }^{6}$ The analyzed data was presented as: Age and gender distribution of the disease, clinical features, laboratory findings, prescription rate of different classes of drugs used, prescription rate of different treatment regimens.

\section{RESULTS}

Case records of 83 patients who were diagnosed with ulcerative colitis based on clinical, endoscopic, and histopathological findings was studied. The mean age of the patients was $40.34 \pm 14.84$ years and peak incidence of disease was in the age group of 30-39 years (Figure 1). Of the 83 patients, $45(54.2 \%)$ were male and $38(45.8 \%)$ were female. The male to female ratio was $1.18: 1$. The common presenting symptoms of the patients were passage of bloody stools $(90 \%)$ and diarrhoea $(86.4 \%)$ followed by abdominal pain $(61.3 \%)$, weight loss $(25.3 \%)$ and fever $(9.6 \%)$ as shown in Figure 2. A few patients had extra-intestinal manifestations such as arthritis (6\%), skin manifestations (6\%) and oral ulcers (3.6\%).

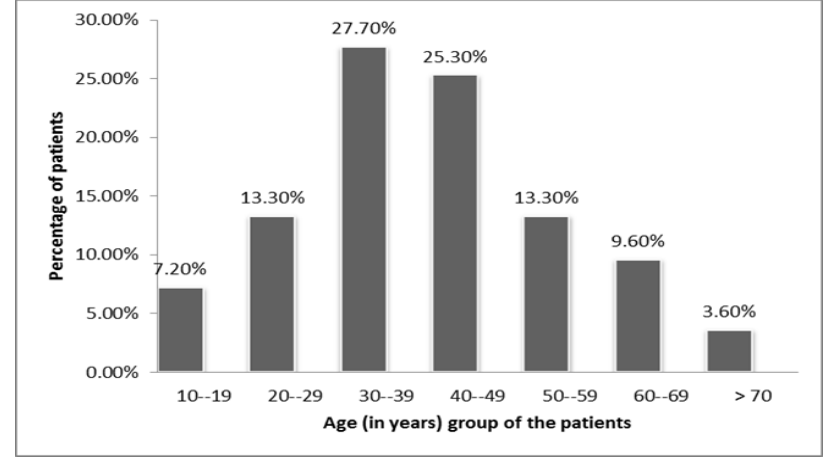

Figure 1: Age distribution of study sample for ulcerative colitis.

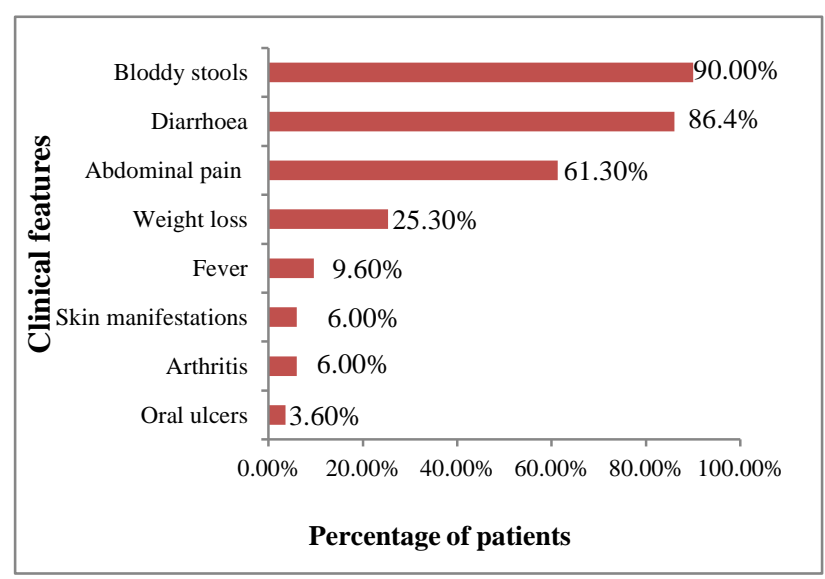

Figure 2: Clinical features of ulcerative colitis.

Hemoglobin levels during initial visit were available for 78 patients. Anemia of varying degrees with hemoglobin level below $12 \mathrm{~g} \%$ was found in 51 patients $(65.4 \%)$ as shown in Table 1. The mean Hb level was 10.85 \pm 2.99 $\mathrm{g} \%$. ESR values were available for 59 patients. Among them, $51(86.4 \%)$ had raised ESR levels.

Table 1: Hemoglobin levels in patients with ulcerative colitis.

\begin{tabular}{|ll|}
\hline Hemoglobin level $(\mathrm{g} \%)$ & Number of patients $(\mathbf{n}=\mathbf{7 8})$ \\
\hline$<8$ & $15(19.2 \%)$ \\
\hline $8-10$ & $15(19.2 \%)$ \\
\hline $10-12$ & $21(26.9 \%)$ \\
\hline$>12$ & $27(34.6 \%)$ \\
\hline
\end{tabular}

Table 2: Prescription rate and route of administration of individual drugs for ulcerative colitis.

\begin{tabular}{|llll|}
\hline Drug class & Individual drug & Prescription rate & Route \\
\hline \multirow{2}{*}{ Aminosalicylates $(\mathrm{n}=78)$} & Mesalamine & $74(94.9 \%)$ & Oral, rectal \\
\cline { 2 - 4 } & Sulfasalazine & $04(5.1 \%)$ & Oral \\
\hline \multirow{2}{*}{ Glucocorticoids $(\mathrm{n}=44)$} & Prednisolone & $41(93.8 \%)$ & Oral \\
\cline { 2 - 4 } & Hydrocortisone & $03(6.2 \%)$ & Intravenous, rectal \\
\hline \multirow{2}{*}{ Immunosuppressants $(\mathrm{n}=15)$} & Azathioprine & $14(93.3 \%)$ & Oral \\
\cline { 2 - 4 } & 6 - MP & $01(6.7 \%)$ & Oral \\
\hline
\end{tabular}


Serum albumin levels were available for 48 patients. Among them, 25 (52.1\%) had decreased serum albumin levels. Out of 83 patients, 81 received pharmacotherapy, 2 patients who were old cases of UC underwent surgery (at the time of data collection), and therefore they were excluded from analysis for drug therapy.

The different classes of drugs prescribed were aminosalicylates, glucocorticoids, and immunosuppressants, 78 patients $(96.3 \%)$ were on aminosalicylates, $44(54.3 \%)$ on glucocorticoids and 15 (18.5\%) received immunosuppressants (Table 2, Figure 3). The most commonly prescribed aminosalicylate was mesalamine $(94.9 \%)$; sulfasalazine was prescribed for 4 patients $(5.1 \%)$. Prednisolone was the commonly used glucocorticoid (93.2\%); hydrocortisone was given only for 3 patients $(6.8 \%)$. Azathioprine was the most commonly prescribed immunosuppressant (93.3\%); 6-mercaptopurine (6-MP) was prescribed for 1 patient $(6.7 \%)$ as shown in Table 2 .

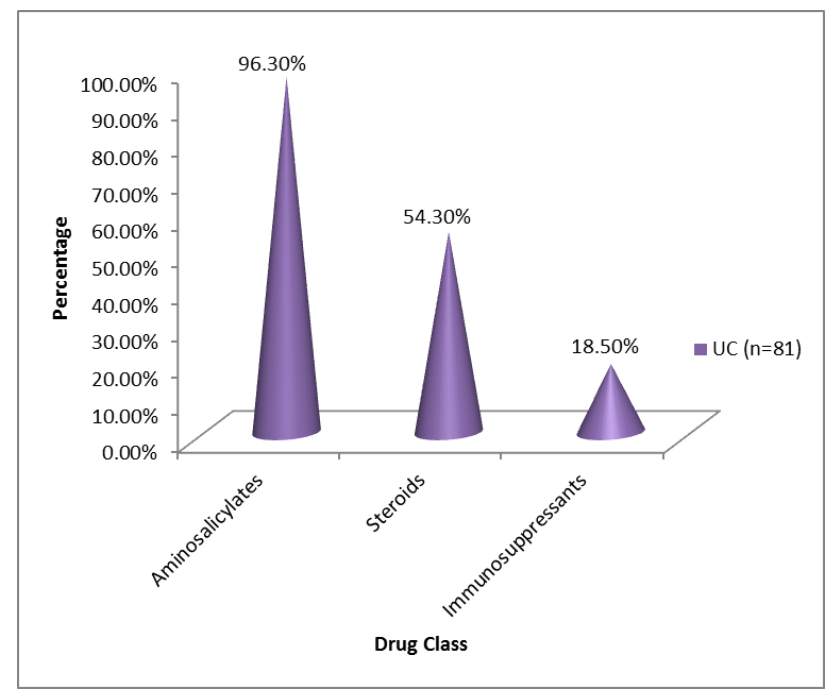

Figure 3: Prescription rate of different class of drugs for ulcerative colitis.

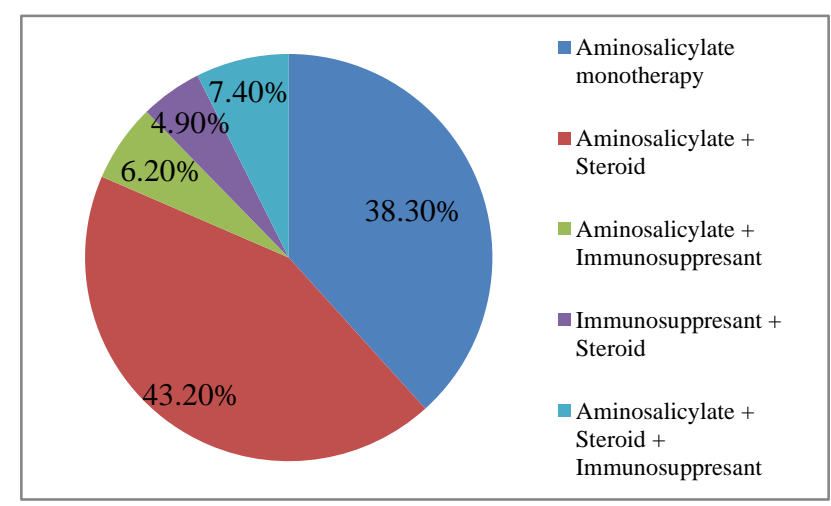

Figure 4: Prescription rate of different treatment regimens for ulcerative colitis.

Out of 81 patients of UC, $31(38.3 \%)$ were started on aminosalicylate monotherapy, $35(43.2 \%)$ on combination of aminosalicylate+steroid, $5(6.2 \%)$ on aminosalicylate + immunosuppressant, $4(4.9 \%)$ on immunosuppressant + steroid and $6(7.4 \%)$ were started on triple drug combination of aminosalicylate + steroid + immunosuppressant (Figure 4). The commonly prescribed treatment regimen was combination of aminosalicylate with steroids $(42.30 \%)$.

Prescription rate of different adjunctive therapy were $48.8 \%, 46.3 \%, 32.1 \%$ and $19.8 \%$ for proton pump inhibitors (PPIs), iron with vitamin supplements, probiotics, antibiotics respectively. In addition, 8 patients $(9.8 \%)$ received blood transfusion.

\section{DISCUSSION}

This study evaluated the drug prescribing pattern in patients with UC in a tertiary care hospital in South India. Our study showed the peak incidence of UC in the age group of 30-39 years. This was similar to other studies done in India. ${ }^{7}$ However our study failed to show the second peak of the disease in the elderly between the age group of 60-70 years which was described in western studies. ${ }^{8}$ In our study, a slight male predominance was seen $(1.18: 1)$ which is in concordance with other Indian studies. ${ }^{7,9,10}$ However, western studies have not shown any gender predominance in the occurrence of ulcerative colitis. ${ }^{8}$ The common presenting symptoms of the patients in our study were passage of bloody stools (90\%) and diarrhea $(86.4 \%)$. Previous studies from India also showed similar findings. ${ }^{10}$

Anemia of varying degrees with hemoglobin level below $12 \mathrm{~g} \%$ was seen in $65.4 \%$ of the patients. This was more when compared to that reported by Tandon et al $(47.6 \%){ }^{9}$ Increase in ESR levels was seen $86.4 \%$ and hypoalbuminemia in $52.1 \%$ patients .

In our study, use of aminosalicylates was more (96.3\%) when compared to immunosuppressants. A similar trend in drug prescription was also reported by Herrinton et al in IBD. ${ }^{11}$ Aminosalicylates are main stay of therapy in mild to moderate UC for both induction and maintenance of remission; this may explain the higher use of these drugs in UC. However, recent studies support a role of immunosuppressants in UC. ${ }^{11}$ The prescription rate of steroids in our study was $54.3 \%$. None of the patients in our study received any of the biologic agents. The probable reason for this may be that conventional drugs have the ability to treat many patients effectively, particularly when used in combination. The other reasons might be the high cost of treatment and serious adverse effects with the use of biologic agents. The different doses of aminosalicylates, glucocorticoids and immunosuppressants used in our study were as per ACG guidelines. $^{12}$

Mesalamine was the commonly prescribed aminosalicylate (dose range 1.2 to $4 \mathrm{~g} /$ day). Sulfasalazine was prescribed only for a few patients and is used in 
doses ranging from 1.5 to $3 \mathrm{~g} /$ day. The lower prescription rate of sulfasalazine in spite of lower cost may be due to the fact that most of the patients may not tolerate it because of side effects produced by sulfapyridine moiety present in sulfasalazine. A recent Cochrane Systematic Review also found a slight benefit of newer 5-ASA preparations over sulfasalazine in induction of remission, when equivalent amounts of the active 5-ASA moiety were compared. ${ }^{12}$ The most common route of administration of mesalamine and sulfasalazine was oral. This may be because of extension of inflammation proximal to the reach of topical therapy, in which oral therapy is required solely or in combination with topical therapy.

Prednisolone was the commonly prescribed steroid (93.2\%). It was administered orally in different doses ranging from 5 to $60 \mathrm{mg} /$ day; most commonly used dose was $40 \mathrm{mg} / \mathrm{day}$. The different doses of prednisolone used in our study were similar to American Gastroenterological Association (AGA) recommendations which had advised 40-60 mg oral prednisolone per day until significant clinical improvement occurs and then the dose is tapered $5-10 \mathrm{mg}$ weekly until the daily dose reaches $20 \mathrm{mg}$. At this point, tapering generally proceeds at $2.5 \mathrm{mg}$ per week. $^{13}$ Azathioprine was the commonly prescribed immunosuppressant (93.3\%). It was administered orally in doses ranging from 25 to $150 \mathrm{mg} /$ day. One patient received 6-MP orally.

The commonly prescribed treatment regimens were combination of aminosalicylates with steroids followed by monotherapy with aminosalicylates. This mainly depends on extent and severity of the disease.

Probiotics and proton pump inhibitors play a supportive role in reducing the symptoms and improve quality of life. Iron and vitamin supplements were used to treat mild to moderate anemia and blood transfusion to treat severe anemia.

\section{CONCLUSION}

Ulcerative colitis was more common in males. Aminosalicylates were the commonly prescribed drugs and a combination of aminosalicylate and steroid was frequently used regimen in our study. The limitations of our study were lack of information on disease severity and long term patient follow up. Ulcerative colitis is a condition which requires lifelong medication. Poor adherence to medication has been an important barrier for successful management of UC. The management of UC also poses some special problems in India. There is often delay in using proper medications, and alternative systems of medicine are still widely used. A combination of western guidelines and regional experiences can be used for induction and maintenance of remission. A stepwise selection of medications is advocated depending on extent, activity and severity of the disease. , $^{3,2}$

Funding: No funding sources

Conflict of interest: None declared

Ethical approval: The study was approved by the Institutional Ethics Committee

\section{REFERENCES}

1. Goligher JC. Ulcerative colitis. In: Surgery of the Anus, Rectum and colon. 3rd edition. London, Bailliere Tindal; 1977:843-1012.

2. Calkins BM, Lilienfeld AM, Garland CF, Mendeloff AI. Trends in the incidence rates of ulcerative colitis and Crohn's disease. Dig Dis Sci. 1984;29:913-20.

3. Ouyang Q, Tandon R, Goh KL, Pan G, Fock KM, Fiocchi $C$, et al. Management consensus on inflammatory bowel disease for the Asia-Pacific region. J Gastroenterol Hepatol. 2006;21(12):1772-82.

4. Lakatos PL. Recent trends in the epidemiology of inflammatory bowel diseases: Up or down? World J Gastroenterol. 2006;12(38):6102-8.

5. Sood A, Midha V, Sood N, Bhatia AS, Avasthi G. Incidence and prevalence of ulcerative colitis in Punjab, North India. Gut. 2003;52(11):1587-90.

6. Narayanareddy M, Shanbhag V, Shanbhag TV, Bhat G, Shenoy S, Gowda A. A retrospective study of the drug prescribing pattern in crohn's disease (CD) in a tertiary care hospital. Int J Pharm Sci Rev Res. 2013;20(1):959.

7. Sood A, Midha V, Sood N, Puri S, Kaushal V. Profile of ulcerative colitis in a North Indian hospital. J Indian Acad Clin Med. 2000;5(2):124-8.

8. Osterman MT, Lichtenstein GR. Ulcerative colitis. In: Feldman M, Friedman LS, Brandt LJ, eds. Sleisenger and Fordtran's Gastrointestinal and liver disease. $9^{\text {th }}$ ed. Philadelphia, Elsevier. 2010:1975-2013.

9. Tandon BN, Mathur K, Mohapatra LN, Tandon HD, Wig KL. A study of the prevalence and clinical pattern of non-specific ulcerative colitis in Northern India. Gut. 1965;6:448-53.

10. Chuttani HK, Nigam SP, Sama SK, Dhanda PC, Gupta PS. Ulcerative colitis in the tropics. $\mathrm{Br}$ Med $\mathrm{J}$. 1967;4:204-7.

11. Herrinton LJ, Liu L, Fireman B, Lewis JD, Allison JE, Flowers N, et al. Time trends in therapies and outcomes for adult inflammatory bowel disease, Northern California, 1998-2005. Gastroenterology. 2009;137:502-11.

12. Kornbluth A, Sachar DB. Ulcerative colitis practice guidelines in adults: American College of Gastroenterology, Practice Parameters Committee. Am J Gastroenterol. 2010;105:501-23.

13. Lichtenstein GR, Abreu MT, Cohen R, Tremaine W. American Gastroenterological Association Institute technical review on corticosteroids, immunomodulators and infliximab in inflammatory bowel disease. Gastroenterology. 2006;130(3):940-87.

Cite this article as: Narayanareddy M, Eesha BR, Shanbhag TV, Shenoy S. Drug prescribing pattern in ulcerative colitis in a tertiary care hospital: an observational study. Int J Basic Clin Pharmacol 2016;5:1862-5. 